\title{
Parameter perturbations in a post-treatment chronic myeloid leukemia model capture the essence of pre-diagnosis A-bomb survivor mysteries
}

\author{
Tomas Radivoyevitch $^{1}$ (D)
}

Received: 15 April 2020 / Accepted: 12 October 2020 / Published online: 30 October 2020

(c) Springer-Verlag GmbH Germany, part of Springer Nature 2020

\begin{abstract}
A model of post-diagnosis chronic myeloid leukemia (CML) dynamics across treatment cessations is applied here to prediagnosis scenarios of A-bomb survivors. The main result is that perturbing two parameters of a two-state simplification of this model captures the essence of two A-bomb survivor mysteries: (1) in those exposed to > $1 \mathrm{~Sv}$ in Hiroshima, four of six female onsets arose as a cluster in 1969-1974, well after 5-10-year latencies expected and observed in two of six femaleand nine of ten male cases (about one background case was expected in this high-dose cohort); and (2) no Nagasaki adult cases exposed to $>0.2 \mathrm{~Sv}$ were observed though about nine were expected ( $\sim 1.5$ background $+\sim 7.5$ radiation-induced). Overall, it is concluded that: (1) whole-body radiation co-creates malignant and benign BCR-ABL clones; (2) benign clones are more likely to act as anti-CML vaccines in females than in males; (3) the Hong Kong flu of 1968 (and H3N2 seasonal flu thereafter) exhausted anti-CML immunity, thereby releasing radiation-induced clones latent in high-dose Hiroshima females; and (4) benign cells of 1-2 are $\mathrm{CD}^{+}$as human T-cell leukemia-lymphoma virus-1 endemic to Nagasaki but not Hiroshima expands numbers of such cells. The next goal is to see if these conclusions can be substantiated using banked A-bomb survivor blood samples.
\end{abstract}

Keywords CML $\cdot$ Immunity $\cdot$ Radiation $\cdot$ TFR $\cdot$ HTLV-1 $\cdot$ H3N2

\section{Introduction}

Chronic myeloid leukemia (CML) arises when BCR-ABL is created in a hematopoietic stem cell (HSC) (Chereda and Melo 2015). This occurs with aging (Radivoyevitch et al. 1999) and with exposures to ionizing radiation (Radivoyevitch and Hoel 1999), reviewed in (Radivoyevitch et al. 2012). Across adult ages, CML incidence is either higher in males by a factor of $\sim 1.6$ or delayed in females by $\sim 10$ years (Radivoyevitch et al. 2014).

Of four groups of A-bomb survivors (two sexes and two cities), for CML, only Hiroshima male data is consistent with non-A-bomb data (Radivoyevitch and Hoel 2000): Hiroshima female radiation-induced CML onsets were too

Tomas Radivoyevitch

radivot@ccf.org

1 Department of Quantitative Health Sciences, Lerner Research Institute, Cleveland Clinic, JJN3-01, 9500 Euclid Ave, Cleveland, OH 44195, USA delayed relative to expectations based on CML incidence in women irradiated for cervical cancer (Inskip et al. 1993; Boice et al. 1987), and Nagasaki risks were too low (Radivoyevitch and Hoel 2000). Specifically, in Hiroshima survivors exposed to $>1 \mathrm{~Sv}, 4$ out of 6 female CML onsets occurred in 1969-1974, well after 5-10-year latencies expected and observed in 2 out of 6 females and 9 out of 10 males (about 1 background case was expected in this cohort, so about 15 out of 16 were radiation-induced), and in Nagasaki adults ( $>20 \mathrm{y}$ ) exposed to $>0.2 \mathrm{~Sv}$, no CML cases were observed where about nine were expected $(\sim 1.5$ background and $\sim 7.5$ radiation-induced). These mysteries have been very difficult to grasp (Radivoyevitch et al. 2019).

Approximately $40 \%$ of CML patients that discontinue therapy after years of use to determine if the drug is still needed reach treatment free remissions (TFR) (Hughes and Ross 2016). Patients attempting this can be classified as either unstable (TFR not reached), strongly stable (TFR reached with no signs of disease), or weakly stable (TFR reached but with BCR-ABL levels still detected by polymerase chain reaction and oscillating as if dynamically 
regulated by the immune system). A mathematical model of CML dynamics across treatment cessations was recently developed (Hahnel et al. 2020). This model is based on earlier models of CML malignant clone interactions with the immune system (Moore and Li 2004; Kim et al. 2008; Paquin et al. 2011; Clapp et al. 2015; Besse et al. 2018; Cesar Fassoni et al. 2019). It was designed for analyses of data arising well after diagnoses. Applying it here to times before diagnoses, it is shown that perturbing two parameters of a two-state simplification of this model captures the essence of the pre-diagnosis mysteries alluded to above, i.e., A-bomb-induced CML onset delays and missingness in Hiroshima and Nagasaki, respectively.

\section{Methods}

The TFR model of (Hahnel et al. 2020) depicted in Fig. 1 represents quiescent CML stem cells $x$, proliferating CML cells $y$, and anti-CML immune cells $z$, as (Eqs. 1-3):

$\frac{d x}{d t}=-p_{x y} x+p_{y x} y$

$\frac{d y}{d t}=p_{x y} x-p_{y x} y+p_{y} y\left(1-\frac{y}{K_{y}}\right)-m y z$

$\frac{d z}{d t}=r_{z}-a z+p_{z} \frac{y}{K_{z}^{2}+y^{2}} z$

where $p_{y x}$ and $p_{x y}$ are transition rate constants into and out of an immune privileged niche of quiescent stem cells, $y$ cells grow with an initial rate constant $p_{y}$ toward a carrying capacity $K_{y}, m$ is the rate constant of immune system killing of CML cells, $\frac{y}{K_{z}^{2}+y^{2}}$ captures the rise (when $y<K_{z}$ )-and-fall (when $y>K_{z}$ ) of immune response amplification as a function of CML load (i.e., $y$ ), $r_{z}$ is a constant flux of $z$ cell creation, $a$ is the $z$ cell apoptosis rate constant, and the initial conditions are $x(0)=0, y(0)=1$, and $z(0)=r_{z} / a$. This model includes parameters for 21 cases (Table 1) obtained via fits

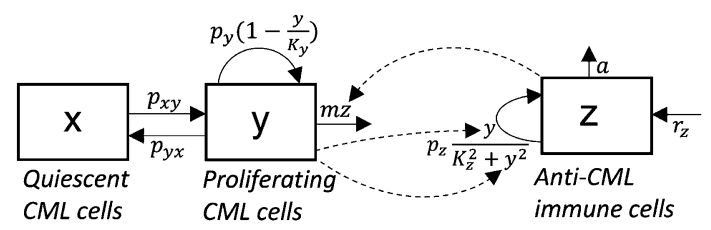

Fig. 1 Treatment-free remission (TFR) model (Hahnel et al. 2020) of CML clone interactions with anti-CML immune cells. Here cells $\mathrm{x}$ are quiescent CML stem cells that live in an immune privileged niche, $\mathrm{y}$ are proliferating CML cells, and $\mathrm{z}$ are anti-CML immune cells to BCR-ABL dynamic responses to tyrosine kinase inhibitor cessation (Hahnel et al. 2020).

\section{Results}

\section{Model adjustment}

Using the parameters in Table 1, Hahnel's post-diagnosis treatment cessation model (Hahnel et al. 2020) was applied here to the pre-diagnosis scenario of starting with one proliferating CML cell (Fig. 2). Patients 6, 12-16, 20 and 21 kept clones subclinical. As these patients were all diagnosed with CML, their parameter values must have changed with time on therapy. All other patients have CML onsets within a year, which is inconsistent with excess CML risks peaking 3-8 years after radiation (Radivoyevitch et al. 2012). To increase onset latencies to about 5 years, $p_{y}=1.66$ was lowered to 0.25 , thus slowing CML clone intrinsic growth. As $p_{y x}$ and $p_{x y}$ are zero in many patients (Table 1 ), to simplify the model, they were set to zero: Eq. (1) then vanishes (eliminating $x$ ) and Eq. (2) becomes $\frac{d y}{d t}=p_{y} y\left(1-\frac{y}{K_{y}}\right)-m y z$. This two-state model is fully described in the Supplement.

Table 1 CML patient parameters for the model of (Hahnel et al. 2020). Held constant were $p_{y}=1.658$, $K_{y}=10^{6}, a=2, r_{z}=200$, and $m=0.0001$. Units are cells and months

\begin{tabular}{lllll}
\hline Patient & $p_{y x}$ & $p_{x y}$ & $p_{z}$ & $K_{z}$ \\
\hline pt1 & 0.01 & 0.05 & 2210 & 362 \\
pt2 & 0 & 0.05 & 1940 & 508 \\
pt3 & 0.88 & 0.18 & 0 & 4.29 \\
pt4 & 0 & 0 & 53,800 & 9570 \\
pt5 & 0 & 0.01 & 176 & 28.7 \\
pt6 & 0.7 & 0.21 & 311,000 & 6480 \\
pt7 & 0 & 0 & 0.01 & 26.3 \\
pt8 & 0 & 0 & 696 & 74.7 \\
pt9 & 0 & 0.07 & 325 & 85.7 \\
pt10 & 0 & 0.04 & 473 & 115 \\
pt11 & 0 & 0 & 2820 & 318 \\
pt12 & 0.04 & 0 & 19,800 & 462 \\
pt13 & 0.11 & 0 & 132,000 & 2120 \\
pt14 & 0.01 & 0 & 54,000 & 1430 \\
pt15 & 0.59 & 0.06 & 82,600 & 1300 \\
pt16 & 0.59 & 0 & 57,600 & 1550 \\
pt17 & 0 & 0.05 & 26,800 & 5700 \\
pt18 & 0 & 0.05 & 0 & 6.84 \\
pt19 & 0 & 0 & 14.7 & 1740 \\
pt20 & 0.01 & 0.04 & 4420 & 419 \\
pt21 & 0.02 & 0.04 & 2530 & 212 \\
\hline
\end{tabular}




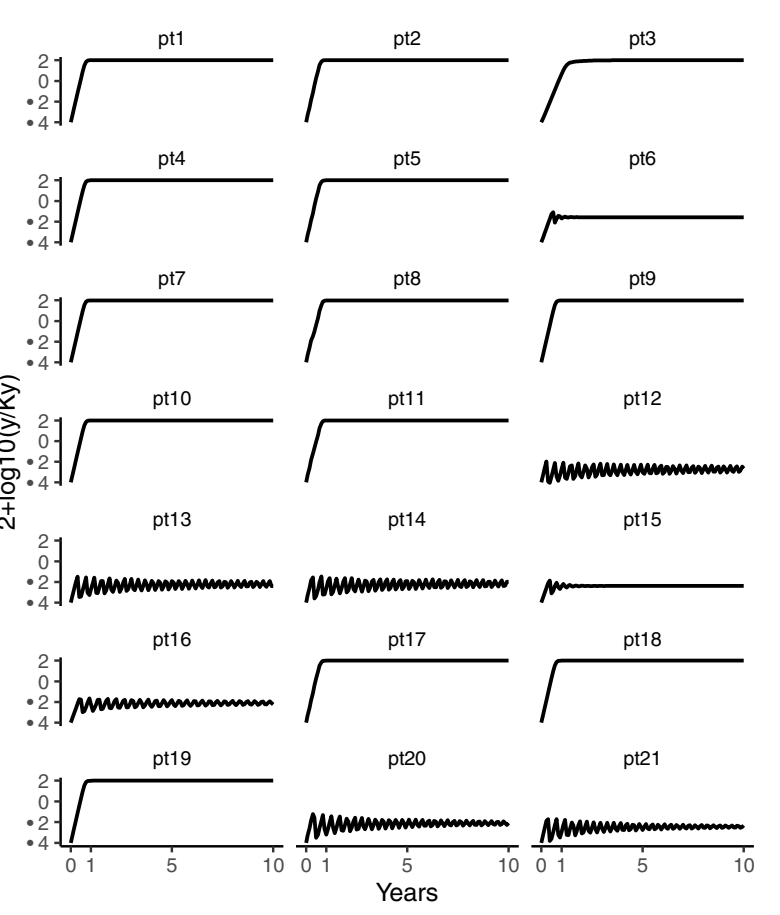

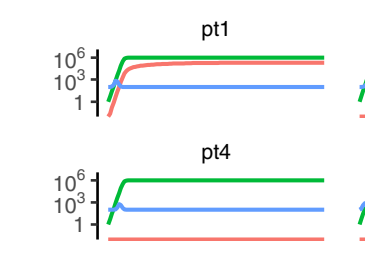

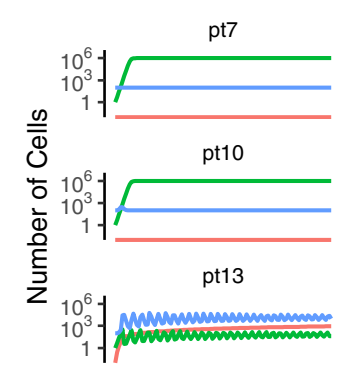

$-x-y-z$
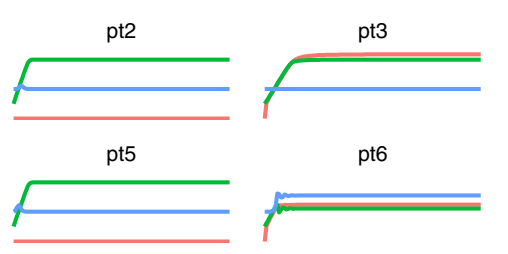

pt6

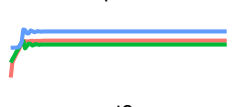

pt8
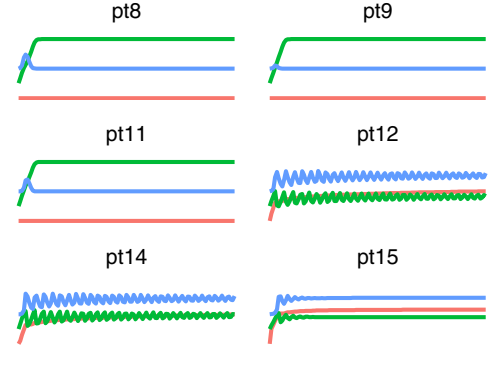

pt12

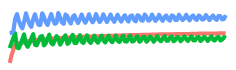

pt15
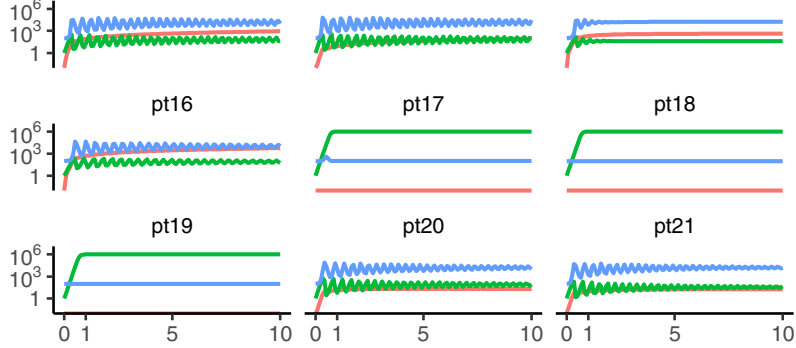

pt20

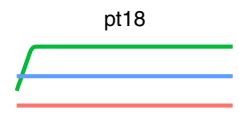

pt21
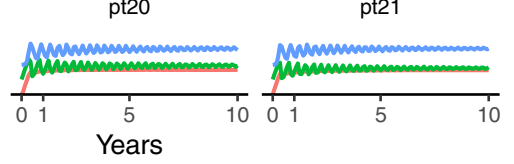

Fig. 2 Simulations of Table 1 model parameters. Left) Log 10 of percent CML cells; the number of normal cells is $K_{y}-y$. Right) Underlying numbers of cells $x, y$ and $z$. R scripts used to generate these plots are available in https://github.com/radivot/myelo/tree/master/CML/tales

\section{Model application}

Let a typical Hiroshima male case be defined by parameter values $p_{y}=0.25, K_{y}=10^{6}, m=0.0001, r_{z}=200, a=2, p_{z}$ $=4000$, and $K_{z}=1000$. Relative to this baseline, to mimic stronger anti-CML immune responses in two-thirds of highdose Hiroshima females, perhaps via cross reactions against a benign clone, the initial number of anti-CML immune cells, $z(0)=r_{z} / a$, was doubled by doubling $r_{z}$; this also doubles the steady state number of anti-CML immune cells present when there are very few or very many CML cells, i.e., when the third term in Eq. (3) is negligible. Relative to these two Hiroshima groups, to mimic stronger immunity (deeper CML suppression) in Nagasaki, $p_{z}$ was increased by $2.5 \%$, i.e., 4100 instead of 4000 (see Supplement). Given these two parameter perturbations, Fig. 3a, b show that in the absence of cross-reactivity, the subclinical stable steady state (first intersection of teal and blue lines) is not reached from $y(0)=1$ and $z(0)=r_{z} / a$, and Fig. $3 \mathrm{c}$, d show that this initial condition reaches the subclinical steady state if cross-reactivity exists (i.e., if $r_{z}=400$ ). Next, to mimic the effects of a lung infection shunting anti-CML immune cells to the lungs wherein they are exhausted, as in a mouse model of influenza exhausting anti-melanoma immune cells (Kohlhapp et al. 2016), $z(t)$ was abruptly set to 0 holding $y(t)$ constant at its stable subclinical steady state value (Figs. 3c, d). After this perturbation, radiation-induced Nagasaki clones returned to their subclinical steady states (Fig. 3c) as two-thirds of highdose ( $>1 \mathrm{~Sv}$ ) Hiroshima females were instead released from immune control and diagnosed as CML (Fig. 3d).

\section{Discussion}

To explain whole- vs. partial-body radiation-induced CML latency differences (Radivoyevitch et al. 2019), it is proposed here that whole-body A-bomb radiation co-creates benign clones that can generate cross-reactive immune responses. The idea is that whole-body radiation exposes many cells to sub-lethal doses, so chances of co-creating a benign clone in a person in which a CML clone was also created are higher than for partial-body therapeutic radiation that either kills cells or leaves them largely untouched. Due to stronger immune competency in females vs. males (Jorgensen 2015), the benign clones may then be more likely to act as anti-CML vaccines in females. To explain benign clone production at about five-fold lower doses in Nagasaki vs. Hiroshima, it is proposed here that the benign clone cells are $\mathrm{CD} 4^{+}$memory cells that expanded about five-fold as a result of human T-cell leukemia-lymphoma virus-1 (HTLV1) (Higuchi et al. 2020). HTLV-1 in Japan separated from HTLV-1 in Africa more than 10,000 years ago (Van Dooren 
Fig. 3 CML control dependence on $p_{\mathrm{z}}$ and $r_{\mathrm{z}}$. Black curves are state trajectories starting at either $y(0)=1$ and $z(0)=r_{z} / a$ or, at $y$ equal to its subclinical stable steady state value and $z=$ 0 to exaggerate flu effects. Blue and teal are $\mathrm{y}$ and $\mathrm{z}$ nullclines where $\mathrm{dy} / \mathrm{dt}$ and $\mathrm{dz} / \mathrm{dt}$ are 0 . These plots can be reproduced using the file Fig. 3 pzrz.R in the folder https://github.com/ radivot/myelo/tree/master/CML/ tales

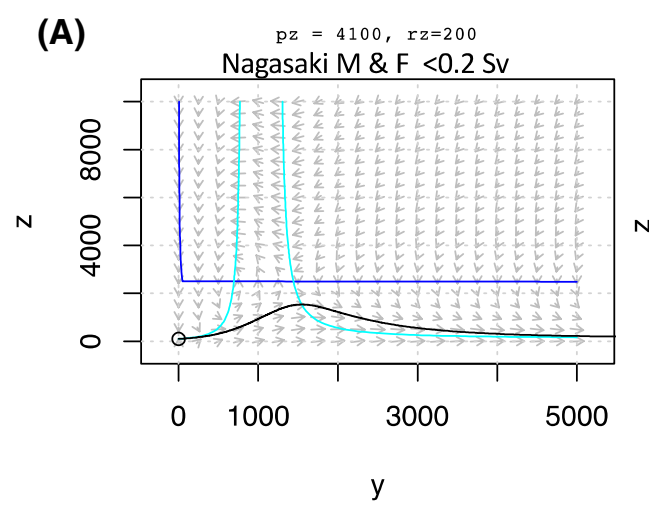

(B)
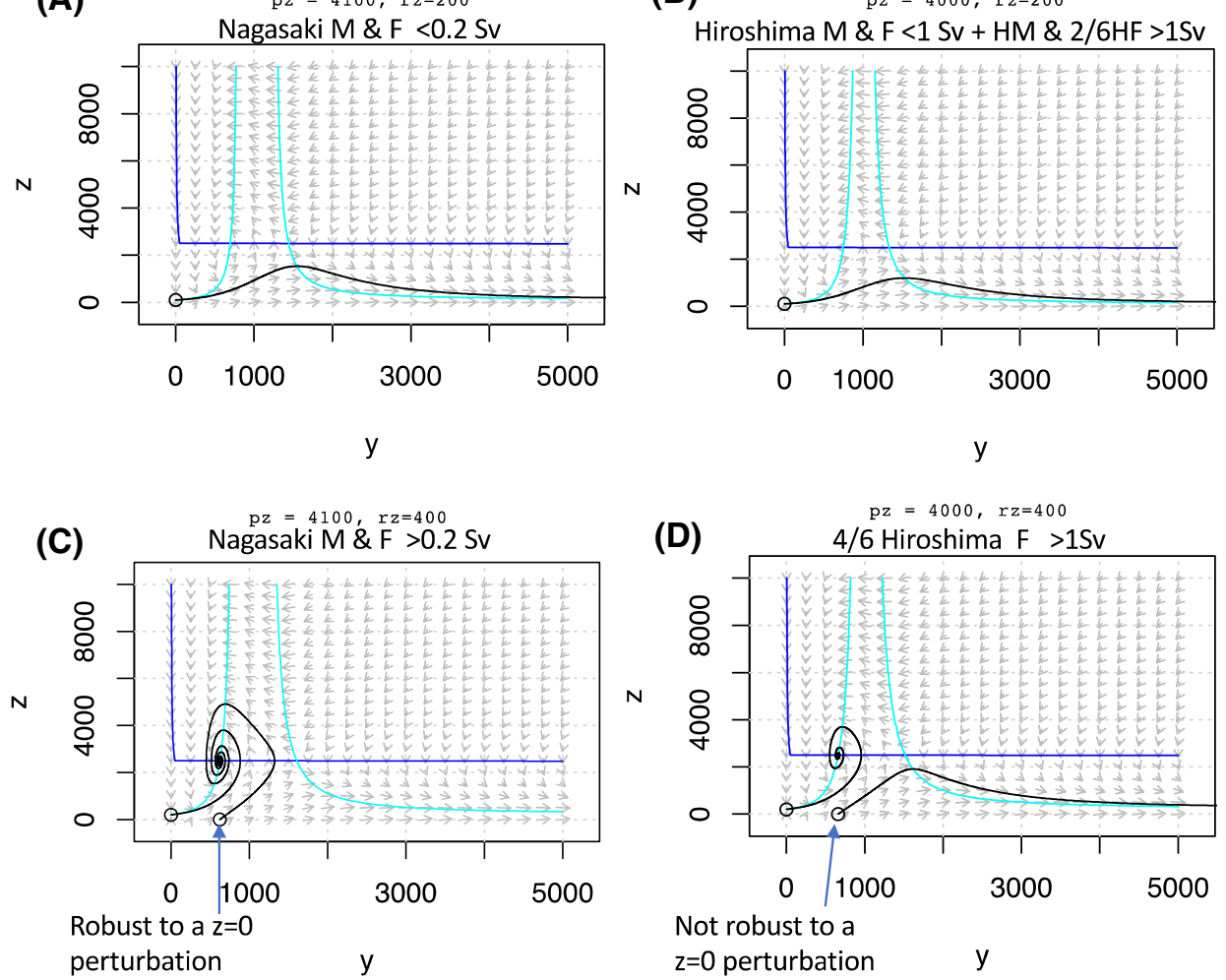

et al. 2001), spreading very slowly via infected $\mathrm{CD} 4^{+}$cells in semen and breast milk (Matsuoka 2005). City differences are thus possible. Indeed, a 20-fold seroprevalence difference in Nagasaki vs. Hiroshima survivors is readily inferred from A-bomb data (Hsu et al. 2013) wherein 44 vs. 5 adult T-cell leukemia/lymphoma (ATL) cases arose in $1.2 \mathrm{vs.}$ 2.7 million person-years at risk in Nagasaki vs. Hiroshima $\left(P<10^{-16}\right)$; HTLV-1 causes ATL (Hinuma et al. 1981), which is not radiation-induced (Preston et al. 1994). To explain subclinical CML in Nagasaki not escaping immunity in 1969-1974, it is proposed here that Nagasaki residents had slightly stronger immune systems than Hiroshima residents ( $p_{z}=4100$ vs. 4000$)$, perhaps because Nagasaki had a longer history of international trade. This small increase of $p_{z}$ sufficed to return a model of TFR to its stable subclinical steady state after perturbations that eliminate existing anti-CML cells, modeled by setting $\mathrm{z}$ to zero to emulate the Hong Kong flu of 1968, which reappeared thereafter as the seasonal H3N2 flu (Allen and Ross 2018). In this model, radiation-induced Hiroshima onsets stop in 1974 because the reservoir of labile subclinical clones was exhausted by then, i.e., all latent Hiroshima clones that could escape immunity via seasonal flu had already done so. As wholebody radiation is needed to create both the malignant CML clone arising from an HSC and the benign protective clone arising from a $\mathrm{CD} 4^{+}$memory cell, one would not expect CML prophylaxis by HTLV-1 in unirradiated populations.
Background CML incidence rates are thus not expected to be lower in endemic HTLV-1 areas, and indeed, in the lowest dose group in Nagasaki, which is just such a population, CML background rates are similar to US background rates (Radivoyevitch et al. 2019).

The observation in females of delays in onsets after whole- but not partial-body radiation (Radivoyevitch et al. 2019) speaks against one BCR-ABL event creating both the benign and the malignant clone in A-bomb survivors. TFRs are different in this regard. In these cases, one BCRABL event may have enough time, after years of therapy, to descend from the founding $\mathrm{HSC}$ to a memory $\mathrm{CD} 4^{+} \mathrm{T}$ cell that then expands to serve as a BCR-ABL junction presenting benign clone that drives immunity against the malignant clone, which after therapy, may be smaller than the benign clone. BCR-ABL existing in T cells in 11 of 20 TFRs (Pagani et al. 2019) supports this. If BCR-ABL in healthy individuals (Biernaux et al. 1995; Bose et al. 1998) lies in $\mathrm{CD}^{+}$cells that expanded via high $\mathrm{ABL}$ activity (Kodama et al. 2020), CML immunity should arise, but two ageinduced BCR-ABL events in one person may be too rare to detect as CML suppression in unirradiated populations.

Proteins produced by HTLV-1 drive $\mathrm{CD}^{+}$cells into Treg states (Higuchi et al. 2020), presumably to expand infected $\mathrm{CD}^{+}{ }^{+}$cell numbers and thus increase HTLV-1 presence in semen and breast milk (Matsuoka and Mesnard 2020). Immunosuppressed microenvironments could help 
nascent $\mathrm{HTLV}-1^{+} \mathrm{CD} 4^{+} \mathrm{BCR}-\mathrm{ABL}^{+}$cells reach larger colony sizes that would aid CML clone suppression by presenting BCR-ABL junction peptides. ABL inhibition lowering HTLV-1 proviral loads (Kodama et al. 2020) suggests that HTLV- ${ }^{+} \mathrm{CD} 4{ }^{+} \mathrm{BCR}-\mathrm{ABL}{ }^{+}$cells likely outcompete HTLV$1^{+} \mathrm{CD} 4^{+}$cells without BCR-ABL. Immunosuppression via $\mathrm{HTLV}-1^{+} \mathrm{CD} 4^{+}$cells without BCR-ABL may thus be minimal. As such, if indeed HTLV-1 suppresses radiationinduced CML, on a per cell basis, each BCR-ABL ${ }^{+} \mathrm{HTLV}$ $1^{+} \mathrm{CD} 4^{+}$cell must activate CML suppression via antigen presentation more than it antagonizes CML suppression via Treg-mediated immune system suppression.

Higher age-specific CML incidence in males could be due to either greater numbers of HSC in males, greater latencies in females, or mixtures thereof (Radivoyevitch et al. 2014). Based on a dead-band control model wherein HSC numbers are not regulated if they lie above a threshold needed to sustain hematopoiesis (Radivoyevitch et al. 2002), HSC number variance may dwarf sex differences. CML incidence overcomes this via large numbers of humans with large numbers of HSC. To deconvolve from CML incidence male and female latencies as functions of age, DNA sequencing reconstructions of HSC numbers over prior ages (Lee-Six et al. 2018) need to be applied to people of both sexes.

Absence of large increases in CML incidence in immunosuppressed individuals (Gale and Opelz 2017) suggests that age-induced CML clone trapping into TFR-like states is not common. The possibility that the immune system always engages, but also always fails, must however be considered, as delays in onsets are more challenging to detect than complete onset absences.

There are two ways to attempt to explain Nagasaki CML missingness without invoking the immune system. One is that HTLV-1 placed enough of a long-term load on HSC to lower their numbers and thus the number of CML target cells. Assuming deadband HSC control (Radivoyevitch et al. 2002), such reductions in target cell numbers would have been permanent. Another is that HTLV-1 altered HSC epigenetic states in ways that destroyed chromosome 9-22 tethering that shortens $B C R$-to- $A B L$ distances (Radivoyevitch et al. 2001), which would have decreased the probability of $B C R$ $A B L$ formation. The problem with these mechanisms is that they would have also reduced background CML incidence in Nagasaki, which was not observed (Radivoyevitch et al. 2019). These explanations also leave delays in Hiroshima females unexplained. CML immunity is the only explanation of both delays in Hiroshima and life-long suppression in Nagasaki (Radivoyevitch et al. 2019).

The mathematical model used here was built on recent post-diagnosis German patient data and applied to prediagnosis states of Japanese A-bomb victims exposed about 60 years earlier. The view taken is that therapy reverses time to a state before diagnosis while biding time for a benign $\mathrm{CD} 4{ }^{+} \mathrm{BCR}-\mathrm{ABL}^{+}$clone to form without whole-body radiation. Regarding race differences, they do exist (Radivoyevitch et al. 2014), but are small relative to other cancers such as chronic lymphocytic leukemia (Gale et al. 2000; Pan et al. 2002; Mak et al. 2014), consistent with CML simplicity relative to other cancers decreasing opportunities for differences to arise.

The Hong Kong flu of 1968, which is now seasonal influenza A H3N2 (Allen and Ross 2018), may have been the perturbagen that released CML subdued in four of six high-dose Hiroshima females. These four cases, prior to their onsets, and about nine Nagasaki subjects with tight enough control that CML never emerged, may have been in essentially TFR states. If so, and if the key flu feature for CML release is lung infection severity, COVID-19 (Guan et al. 2020) might then be predicted to cause relapses in Hiroshima-female-like TFRs but not Nagasaki-like TFRs. In Table 1, six patients were Hiroshima male-like in that they did not have a stable subclinical steady state [see Class A of (Hahnel et al. 2020)], eight were Nagasaki-like in that they had very stable subclinical steady states (easy to reach and easy to return to due to strong immunity) [see Class B of (Hahnel et al. 2020)], and seven were Hiroshima-female like in that they had labile stable subclinical steady states (harder to reach but reachable, and easier to exit) [see Class $\mathrm{C}$ of (Hahnel et al. 2020)]. If these proportions are representative of CML patients in general, COVID-19 infections may break about $50 \%$ of TFRs.

The model used was developed for post-diagnosis CML data (Hahnel et al. 2020). Novel here are its modifications, its application to pre-diagnosis scenarios, details of how to perturb it to represent A-bomb survivor subgroups and flu effects, and the mapping of patient Classes A-C (Hahnel et al. 2020) to CML in Hiroshima males, Nagasaki, and two-thirds of high-dose Hiroshima females. Importantly, understanding Hiroshima CML onset delays and Nagasaki onset missingness may help researchers find ways to drive unstable Class A patients to subclinical Class C or B states. It may also lead them to consider the possibility that abscopal effects (Poleszczuk et al. 2016) may be rare because they arise via radiation-induced cell vaccine induction, rather than antigens released by killing cancer cells.

As CML is simple, it was baffling that of four sex-city A-bomb groups, consistency with non-A-bomb data existed only for Hiroshima males (Radivoyevitch and Hoel 2000). Satisfactory explanations were still lacking many years later (Radivoyevitch et al. 2019). COVID-19 then yielded the missing pieces: it led the author to learn that $\mathrm{H} 3 \mathrm{~N} 2$ became a seasonal flu starting in 1968 (Allen and Ross 2018) and that the flu attracts anti-cancer immune cells to lungs wherein they are exhausted (Kohlhapp et al. 2016). With these pieces, and support of TFR data via its model, the author now firmly believes that: (1) whole-body radiation co-creates malignant 
and benign BCR-ABL clones; (2) benign clones are more likely to act as anti-CML vaccines in females than in males; (3) the Hong Kong flu of 1968 exhausted anti-CML immunity, causing four Hiroshima female radiation-induced cases to cluster in 1969-1974; and (4) the benign clone cells in 1-2 are $\mathrm{CD} 4^{+}$. The next goal is to determine if some of these conclusions, particularly 1 and 4 , can be substantiated via single cell deep sequencing (Giustacchini et al. 2017) of banked A-bomb survivor blood samples that presumably exist at the Radiation Effects Research Foundation in Japan.

Acknowledgements I thank Professor Werner Rühm for his excellent edits and suggestions, two anonymous reviewers for their input, and the Cleveland Clinic for its support. This report makes use of data obtained from the Radiation Effects Research Foundation (RERF), Hiroshima and Nagasaki, Japan. RERF is a public interest foundation funded by the Japanese Ministry of Health, Labor and Welfare (MHLW) and the US Department of Energy (DOE), the latter in part through DOE award DE-HS0000031 to the National Academy of Sciences. The conclusions in this report are those of the author and do not necessarily reflect the scientific judgment of RERF or its funding agencies.

\section{Compliance with ethical standards}

Conflict of interest The author(s) declare that they have no competing interests.

\section{References}

Allen JD, Ross TM (2018) H3N2 influenza viruses in humans: viral mechanisms, evolution, and evaluation. Hum Vaccin Immunother 14(8):1840-1847. https://doi.org/10.1080/21645515.2018.14626 39

Besse A, Clapp GD, Bernard S, Nicolini FE, Levy D, Lepoutre T (2018) Stability analysis of a model of interaction between the immune system and cancer cells in chronic myelogenous leukemia. Bull Math Biol 80(5):1084-1110. https://doi.org/10.1007/ s11538-017-0272-7

Biernaux C, Loos M, Sels A, Huez G, Stryckmans P (1995) Detection of major bcr-abl gene expression at a very low level in blood cells of some healthy individuals. Blood 86(8):3118-3122

Boice JD Jr, Blettner M, Kleinerman RA, Stovall M, Moloney WC, Engholm G, Austin DF, Bosch A, Cookfair DL, Krementz ET (1987) Radiation dose and leukemia risk in patients treated for cancer of the cervix. J Natl Cancer Inst 79(6):1295-1311

Bose S, Deininger M, Gora-Tybor J, Goldman JM, Melo JV (1998) The presence of typical and atypical BCR-ABL fusion genes in leukocytes of normal individuals: biologic significance and implications for the assessment of minimal residual disease. Blood 92(9):3362-3367

Cesar Fassoni A, Roeder I, Glauche I (2019) To cure or not to cure: consequences of immunological interactions in CML treatment. Bull Math Biol 81(7):2345-2395. https://doi.org/10.1007/s1153 8-019-00608-x

Chereda B, Melo JV (2015) Natural course and biology of CML. Ann Hematol 94(Suppl 2):S107-121. https://doi.org/10.1007/s0027 7-015-2325-z

Clapp GD, Lepoutre T, El Cheikh R, Bernard S, Ruby J, LabussiereWallet H, Nicolini FE, Levy D (2015) Implication of the autologous immune system in BCR-ABL transcript variations in chronic myelogenous leukemia patients treated with imatinib. Cancer Res 75(19):4053-4062. https://doi.org/10.1158/0008-5472. CAN-15-0611

Gale RP, Opelz G (2017) Is there immune surveillance against chronic myeloid leukaemia? Possibly, but not much. Leuk Res 57:109111. https://doi.org/10.1016/j.leukres.2017.03.003

Gale RP, Cozen W, Goodman MT, Wang FF, Bernstein L (2000) Decreased chronic lymphocytic leukemia incidence in Asians in Los Angeles county. Leuk Res 24(8):665-669

Giustacchini A, Thongjuea S, Barkas N, Woll PS, Povinelli BJ, Booth CAG, Sopp P, Norfo R, Rodriguez-Meira A, Ashley N, Jamieson L, Vyas P, Anderson K, Segerstolpe A, Qian H, Olsson-Stromberg U, Mustjoki S, Sandberg R, Jacobsen SEW, Mead AJ (2017) Single-cell transcriptomics uncovers distinct molecular signatures of stem cells in chronic myeloid leukemia. Nat Med 23(6):692-702. https://doi.org/10.1038/nm.4336

Guan WJ, Ni ZY, Hu Y, Liang WH, Ou CQ, He JX, Liu L, Shan H, Lei CL, Hui DSC, Du B, Li LJ, Zeng G, Yuen KY, Chen RC, Tang CL, Wang T, Chen PY, Xiang J, Li SY, Wang JL, Liang ZJ, Peng YX, Wei L, Liu Y, Hu YH, Peng P, Wang JM, Liu JY, Chen Z, Li G, Zheng ZJ, Qiu SQ, Luo J, Ye CJ, Zhu SY, Zhong NS, China Medical Treatment Expert Group for C (2020) Clinical characteristics of coronavirus disease 2019 in China. N Engl J Med. https ://doi.org/10.1056/NEJMoa2002032

Hahnel T, Baldow C, Guilhot J, Guilhot F, Saussele S, Mustjoki S, Jilg S, Jost PJ, Dulucq S, Mahon FX, Roeder I, Fassoni AC, Glauche I (2020) Model-based inference and classification of immunological control mechanisms from TKI cessation and dose reduction in CML patients. Cancer Res. https://doi.org/10.1158/0008-5472. CAN-19-2175

Higuchi Y, Yasunaga JI, Mitagami Y, Tsukamoto H, Nakashima K, Ohshima K, Matsuoka M (2020) HTLV-1 induces T cell malignancy and inflammation by viral antisense factor-mediated modulation of the cytokine signaling. Proc Natl Acad Sci USA 117(24):13740-13749. https://doi.org/10.1073/pnas.1922884117

Hinuma Y, Nagata K, Hanaoka M, Nakai M, Matsumoto T, Kinoshita KI, Shirakawa S, Miyoshi I (1981) Adult T-cell leukemia: antigen in an ATL cell line and detection of antibodies to the antigen in human sera. Proc Natl Acad Sci USA 78(10):6476-6480. https:// doi.org/10.1073/pnas.78.10.6476

Hsu WL, Preston DL, Soda M, Sugiyama H, Funamoto S, Kodama K, Kimura A, Kamada N, Dohy H, Tomonaga M, Iwanaga M, Miyazaki Y, Cullings HM, Suyama A, Ozasa K, Shore RE, Mabuchi K (2013) The incidence of leukemia, lymphoma and multiple myeloma among atomic bomb survivors: 1950-2001. Radiat Res 179(3):361-382. https://doi.org/10.1667/RR2892.1

Hughes TP, Ross DM (2016) Moving treatment-free remission into mainstream clinical practice in CML. Blood 128(1):17-23. https ://doi.org/10.1182/blood-2016-01-694265

Inskip PD, Kleinerman RA, Stovall M, Cookfair DL, Hadjimichael O, Moloney WC, Monson RR, Thompson WD, Wactawski-Wende J, Wagoner JK (1993) Leukemia, lymphoma, and multiple myeloma after pelvic radiotherapy for benign disease. Radiat Res 135(1): $108-124$

Jorgensen TN (2015) Sex disparities in the immune response. Cell Immunol 294(2):61-62. https://doi.org/10.1016/j.celli mm.2015.02.001

Kim PS, Lee PP, Levy D (2008) Dynamics and potential impact of the immune response to chronic myelogenous leukemia. PLoS Comp Biol 4(6):e1000095. https://doi.org/10.1371/journal.pcbi.1000095

Kodama D, Tanaka M, Matsuzaki T, Izumo K, Nakano N, Matsuura E, Saito M, Nagai M, Horiuchi M, Utsunomiya A, Takashima H, Kubota R, Izumo S (2020) Inhibition of ABL1 tyrosine kinase reduces HTLV-1 proviral loads in peripheral blood mononuclear cells from patients with HTLV-1-associated myelopathy/tropical 
spastic paraparesis. PLoS Negl Trop Dis 14(7):e0008361. https:// doi.org/10.1371/journal.pntd.0008361

Kohlhapp FJ, Huelsmann EJ, Lacek AT, Schenkel JM, Lusciks J, Broucek JR, Goldufsky JW, Hughes T, Zayas JP, Dolubizno H, Sowell RT, Kuhner R, Burd S, Kubasiak JC, Nabatiyan A, Marshall S, Bommareddy PK, Li S, Newman JH, Monken CE, Shafikhani SH, Marzo AL, Guevara-Patino JA, Lasfar A, Thomas PG, Lattime EC, Kaufman HL, Zloza A (2016) Non-oncogenic acute viral infections disrupt anti-cancer responses and lead to accelerated cancer-specific host death. Cell Rep 17(4):957-965. https://doi.org/10.1016/j.celrep.2016.09.068

Lee-Six H, Obro NF, Shepherd MS, Grossmann S, Dawson K, Belmonte M, Osborne RJ, Huntly BJP, Martincorena I, Anderson E, O'Neill L, Stratton MR, Laurenti E, Green AR, Kent DG, Campbell PJ (2018) Population dynamics of normal human blood inferred from somatic mutations. Nature 561(7724):473-478. https://doi.org/10.1038/s41586-018-0497-0

Mak V, Ip D, Mang O, Dalal C, Huang S, Gerrie A, Gillan T, Ramadan KM, Toze C, Au WY (2014) Preservation of lower incidence of chronic lymphocytic leukemia in Chinese residents in British Columbia: a 26-year survey from 1983 to 2008. Leuk Lymphoma 55(4):824-827. https://doi.org/10.3109/10428194.2013.827785

Matsuoka M (2005) Human T-cell leukemia virus type I (HTLV-I) infection and the onset of adult T-cell leukemia (ATL). Retrovirology 2:27. https://doi.org/10.1186/1742-4690-2-27

Matsuoka M, Mesnard JM (2020) HTLV-1 bZIP factor: the key viral gene for pathogenesis. Retrovirology 17(1):2. https://doi. org/10.1186/s12977-020-0511-0

Moore H, Li NK (2004) A mathematical model for chronic myelogenous leukemia (CML) and $\mathrm{T}$ cell interaction. $\mathrm{J}$ of Theor Biol 227(4):513-523. https://doi.org/10.1016/j.jtbi.2003.11.024

Pagani IS, Dang P, Saunders VA, Grose R, Shanmuganathan N, Kok $\mathrm{CH}$, Carne L, Rwodzi Z, Watts S, McLean J, Braley J, Altamura H, Yeung DT, Branford S, Yong ASM, White DL, Hughes TP, Ross DM (2019) Lineage of measurable residual disease in patients with chronic myeloid leukemia in treatment-free remission. Leukemia. https://doi.org/10.1038/s41375-019-0647-x

Pan JW, Cook LS, Schwartz SM, Weis NS (2002) Incidence of leukemia in Asian migrants to the United States and their descendants. Cancer Causes Control 13(9):791-795

Paquin D, Kim PS, Lee PP, Levy D (2011) Strategic treatment interruptions during imatinib treatment of chronic myelogenous leukemia. Bull Math Biol 73(5):1082-1100. https://doi.org/10.1007/s1153 8-010-9553-0

Poleszczuk JT, Luddy KA, Prokopiou S, Robertson-Tessi M, Moros EG, Fishman M, Djeu JY, Finkelstein SE, Enderling H (2016)
Abscopal benefits of localized radiotherapy depend on activated T-cell trafficking and distribution between metastatic lesions. Cancer Res 76(5):1009-1018. https://doi.org/10.1158/0008-5472. CAN-15-1423

Preston DL, Kusumi S, Tomonaga M, Izumi S, Ron E, Kuramoto A, Kamada N, Dohy H, Matsuo T, Matsui T (1994) Cancer incidence in atomic bomb survivors. Part III. Leukemia, lymphoma and multiple myeloma, 1950-1987. Radiat Res 137(2 Suppl):S68-S97

Radivoyevitch T, Hoel DG (1999) Modeling the low-LET doseresponse of BCR-ABL formation: predicting stem cell numbers from A-bomb data. Math Biosci 162(1-2):85-101

Radivoyevitch T, Hoel DG (2000) Biologically-based risk estimation for radiation-induced chronic myeloid leukemia. Radiat Environ Biophys 39(3):153-159

Radivoyevitch T, Ramsey MJ, Tucker JD (1999) Estimation of the target stem-cell population size in chronic myeloid leukemogenesis. Radiat Environ Biophys 38(3):201-206

Radivoyevitch T, Kozubek S, Sachs RK (2001) Biologically based risk estimation for radiation-induced CML. Inferences from BCR and ABL geometric distributions. Radiat Environ Biophys 40(1):1-9

Radivoyevitch T, Kozubek S, Sachs RK (2002) The risk of chronic myeloid leukemia: can the dose-response curve be U- shaped? Radiat Res 157(1):106-109

Radivoyevitch T, Hlatky L, Landaw J, Sachs RK (2012) Quantitative modeling of chronic myeloid leukemia: insights from radiobiology. Blood 119(19):4363-4371. https://doi.org/10.1182/blood -2011-09-381855

Radivoyevitch T, Jankovic GM, Tiu RV, Saunthararajah Y, Jackson RC, Hlatky LR, Gale RP, Sachs RK (2014) Sex differences in the incidence of chronic myeloid leukemia. Radiat Environ Biophys 53(1):55-63. https://doi.org/10.1007/s00411-013-0507-4

Radivoyevitch T, Jorgensen TN, Lindner DJ, Maciejewski JP, Miyazaki Y, Gale RP (2019) Chronic myeloid leukemia: two mysteries. Leuk Res 79:3-5. https://doi.org/10.1016/j.leukres.2019.02.003

Van Dooren S, Salemi M, Vandamme AM (2001) Dating the origin of the African human T-cell lymphotropic virus type-i (HTLV-I) subtypes. Mol Biol Evol 18(4):661-671. https://doi.org/10.1093/ oxfordjournals.molbev.a003846

Publisher's Note Springer Nature remains neutral with regard to jurisdictional claims in published maps and institutional affiliations. 